\title{
MALFORMAÇÕES CONGÊNITAS RELACIONADAS AO SISTEMA NERVOSO DE RECÉM-NASCIDOS DAS MACRORREGIÕES DO ESTADO DO CEARÁ
}

\section{CONGENITAL MALFORMATIONS RELATED TO THE NEWBORN SYSTEM OF THE CEARÁ STATE MACROREGIONS}

\author{
Rívio Fabrício de Figueirêdo Furtado ${ }^{1}$ \\ Rodrigo Lacerda Carvalho ${ }^{2}$ \\ Edicarlos Pereira de Sousa ${ }^{3}$ \\ Vanessa Erika Abrantes Coutinho ${ }^{4}$ \\ Jessica Alves Moreira ${ }^{5}$ \\ Mariana Gomes Pinto ${ }^{6}$
}

RESUMO: OBJETIVO: Analisar dados do levantamento de nascidos vivos com malformações congênitas do sistema nervoso. MÉTODO: A pesquisa trata-se de um estudo epidemiológico do tipo transversal, exploratório, com dados obtidos pelo sistema de informação do SUS. As informações colhidas pelo DATASUS foram direcionadas às malformações congênitas do sistema nervoso, visando detectar fatores relevantes para os casos encontrados na macrorregião do Estado do Ceará. Os gráficos foram obtidos através do programa da Microsoft, o Excel Office 365, mediante transferência dos dados retirados de tabelas visualizadas no DATASUS. Essas informações nortearam a pesquisa. RESULTADOS: Foram encontrados dados significativos para a macrorregião de Fortaleza e Cariri Cearense no período compreendido entre 2015 e 2016, devido ao surto do vírus Zika que, na época, estava em ascensão. Com relação a idade materna relacionada aos casos de defeitos congênitos, se destacaram a faixa etária entre 15 a 34 anos, considerado

\footnotetext{
1 Licenciado em Biologia pela Universidade Federal do Cariri, Brejo Santo - Ceará, Brasil. E-mail: rivio.fabricio@hotmail.com.

2 Licenciado em Matemática. Doutor em Educação Brasileira pela UFC. Professor da Universidade Federal do Cariri campus Brejo Santo - CE.

3 Licenciado em Ciências e Matemática. Doutor em Meteorologia pela UFCG. Professor da Universidade Federal do Cariri campus Brejo Santo - CE.

${ }^{4}$ Licenciada e Bacharela em Ciências Biológicas. Mestre em Biologia Celular e Molecular. Professora substituta da Universidade Federal do Cariri, campus Brejo Santo - CE e Professora da Faculdade Santa Maria - FSM.

${ }^{5}$ Biomédica. Especialista em Hematologia clínica pela UNILEÃO e em Docência do Ensino Superior pela FSM. Professora da Faculdade Santa Maria - FSM.

${ }^{6}$ Acadêmica do curso de Fisioterapia da Faculdade Santa Maria - FSM.
} 
como período fértil das mulheres. CONCLUSÃO: No Ceará, foi evidente a presença desse agente patogênico, sendo descritos casos em vinte e duas regiões, em especial na macrorregião de Fortaleza que concentrou o maior número, num total acima de $50 \%$, confirmando que nessa região há a necessidade de mais atenção das agências de saúde. O diagnóstico precoce é essencial para a análise da gravidade dos defeitos congênitos causados nos recém-nascidos, desde que se tenha o tratamento adequado para a sobrevida dos bebês e acompanhamento das mães afetadas. Este estudo demonstrou as particularidades inerentes a pesquisas epidemiológicas e que podem direcionar as autoridades governamentais para o investimento de campanhas na informação da população para a prática preventiva contra o surgimento do mosquito Aedes aegypti, transmissor do vírus Zika.

Palavras chave: Sistema Nervoso. Malformações Congênitas. Macrorregiões do Ceará.

ABSTRACT: OBJECTIVE: To analyze data from the survey of live births with congenital malformations of the nervous system. METHOD: The research is an exploratory cross-sectional epidemiological study with data obtained from the SUS information system. The information collected by DATASUS was directed to congenital malformations of the nervous system, aiming to detect factors relevant to the cases found in the macroregion of Ceará State. The graphs were obtained through the Microsoft Excel Office 365 program, by transferring data from tables viewed in DATASUS. This information guided the research. RESULTS: Significant data were found for the Fortaleza and Cariri Cearense macroregions between 2015 and 2016, due to the rising Zika virus at the time. Regarding maternal age related to cases of birth defects, the age group between 15 and 34 years old, considered as the fertile period of women, stood out. CONCLUSION: In Ceará, the presence of this pathogen was evident, and cases were described in twenty-two regions, especially in the macroregion of Fortaleza, which concentrated the largest number, totaling over $50 \%$, confirming that there is a need for more attention from these regions health agencies. Early diagnosis is essential for the analysis of the severity of birth defects caused in newborns, provided adequate treatment is available for the survival of infants and follow-up of affected mothers. This study demonstrated the peculiarities inherent in epidemiological research and that may direct government authorities to invest in information campaigns to prevent the emergence of the Aedes aegypti mosquito, transmitter of the Zika virus.

Keywords: Nervous system. Congenital Malformations. Macroregion of Ceará. 


\section{INTRODUÇÃO}

O Sistema Nervoso (SN) surge entre a terceira e quarta semana de gestação pelo processo chamado de neurulação. Nesse evento, são formados a placa neural e o tubo neural, diferenciando-se no Sistema Nervoso Central em cérebro e medula espinal (MOORE, PERSAUD, TORCHIA, 2016).

Devido a sua importância no funcionamento do organismo, qualquer malformação que atinge esse sistema pode gerar sérias consequências para o recém-nascido. Essas disfunções podem ser classificadas em isoladas ou associadas, apresentando-se como físicas, mentais, simples, múltiplas e que variam em importância clínica (GARNE et al., 2011).

Segundo a Organização Pan-Americana de Saúde (1984), malformações congênitas são todas as alterações em um órgão ou conjunto de órgãos que caracterize uma anomalia morfológica estrutural ou funcional, estando presente ou não no nascimento, e que podem estar associada a fatores genéticos, ambientais ou mistos.

Dentre as malformações associadas ao Sistema Nervoso estão presentes a Espinha Bifida Oculta, Espinha Bifida Cística, Crânio Bifido, Meroencefalia, Microcefalia, Hidrocefalia, Malformação de Chiari, entre outras (SADLER, 2013).

Os defeitos congênitos relacionados à medula espinal, como a Espinha Bífida, ocorrem entre a terceira e quarta semana de desenvolvimento embrionário, ocasionados por falhas nos arcos neurais das vértebras. Essa anomalia pode atingir várias regiões da medula e a localização estrutural define o prognóstico, sendo $90 \%$ dos casos na região lombossacra (SIMONI et al., 2013).

Outra malformação da medula espinal é a Espinha Bífida Cística, é a forma grave, envolve protrusão de arcos ou meninges também devido a falhas na fusão dos arcos neurais de vértebras e presença de um saco cístico (AGUIAR et al., 2003).

$\mathrm{Na}$ região do crânio, a partir da quarta semana de gestação, o mau fechamento do neuróporo rostral provoca malformações congênitas ligadas às 
meninges e ao crânio. Esse defeito cerebral é conhecido como Crânio Bífido. Em casos menos grave, observa-se herniação das meninges e são denominadas meningocele craniana (MAYA, 2002).

A Meroencefalia é um defeito que apresenta ausência de partes importantes do cérebro como o prosencéfalo, o mesencéfalo e rombencéfalo além do crânio, sendo uma falha no fechamento do neuróporo rostral e está ligada a fatores genéticos, nutricionais e ambientais (MOORE, PRESUAD, TORCHIA, 2016).

A Microcefalia está associada a problemas neurológicos e apresenta crânio e cérebro pequenos, prejudicando o desenvolvimento mental desses bebês. Pode está ligada a fatores genéticos autossômicos recessivos e fatores ambientais como infecção in utero por citomegalovírus (VARGAS et al., 2016).

Conforme indicado na literatura médica, outras malformações relacionadas ao SN são a Hidrocefalia que é o aumento do volume da cabeça devido a um distúrbio da circulação e absorção do liquor, proporcionado por um estreitamento do aqueduto cerebral e a Malformação de Chiari que é um defeito estrutural do cerebelo em que a fossa craniana exerce pressão sobre o cerebelo e o tronco cerebral, obstruindo a absorção e fluxo do liquor (HADŽAGIĆ-ĆATIBUŠIĆ et al., 2008).

Segundo Yadav (2016), no século XXI, os casos de doenças relacionadas ao sistema nervoso aumentaram devido a ação de um vírus denominado de Zika vírus, transmitido por meio da picada de um mosquito. Os flavivírus são apontados entre as viroses conhecidas como uma das mais importantes para os seres humanos, sendo a mais recente e provocada por artrópodes.

O Aedes aegypti está presente em muitas regiões das Américas, podendo ser encontrado próximo das residências, em locais que possam apresentar condições favoráveis para seu desenvolvimento, como água parada em vasilhames, onde são postos seus ovos, e atuam durante o período diurno, picando suas vítimas (YOUNGER, 2016).

Vale ressaltar a importância de estudar as malformações congênitas do sistema nervoso, prevalência, causas, tipos e prevenção dessas anomalias. Para embasamento, lançou-se mão de ferramentas matemáticas para análise dessas variáveis. Salienta-se ainda um aspecto importante para o aprofundamento do tema que é o interesse dos profissionais na área da saúde. 
Outro instrumento de colaboração é o Departamento de Informática do Sistema Único de Saúde (DATASUS) que é um dispositivo eletrônico utilizado no Brasil como meio de acessibilidade de dados vinculados aos problemas da sociedade clínica e epidemiológica, gerenciado pelo Ministério da Saúde e responsável pela coleta, processamento e disseminação de informações sobre saúde (DATASUS, 1991).

O levantamento de informações sobre as malformações congênitas merece destaque devido sua importância na área médica e prognóstico para a sobrevida de recém-nascidos. Diante da problemática, o presente estudo teve como objetivo geral: analisar dados do levantamento de nascidos vivos com malformações congênitas do sistema nervoso no Ceará. Os objetivos específicos foram: i) enumerar a quantidade de nascidos vivos com e sem malformações congênitas nas macrorregiões do Estado do Ceará; ii) comparar o número de malformações do sistema nervoso com o total encontrado na região pesquisada e iii) verificar a ocorrência desses defeitos congênitos com a idade materna.

\section{METODOLOGIA}

Esta pesquisa configura-se como um estudo epidemiológico do tipo transversal, exploratório, com dados obtidos pelo programa de informação do Sistema Único de Saúde. Os dados colhidos pelo Departamento de Informações do SUS foram os relacionados às malformações congênitas do sistema nervoso, visando detectar fatores relevantes para os casos encontrados nas macrorregiões do Estado do Ceará.

Foram acessados os portais Scielo, Bireme e o Google Acadêmico para se obter informações relacionadas ao tema. Os descritores norteadores para a pesquisa foram: malformações congênitas, sistema nervoso e macrorregiões do Estado do Ceará.

Os gráficos foram obtidos através do programa da Microsoft, o Excel Office 365, mediante transferência dos dados retirados de tabelas visualizadas no 
DATASUS. O período de análise dos dados foi de 2012 a 2016. Essas informações nortearam a pesquisa.

As macrorregiões escolhidas para destacar esse problema epidemiológico foram Fortaleza e Cariri Cearense, por apresentar característica como estações fixas de chuva e de seca, condição que propicia o desenvolvimento do mosquito que transmite dengue, chikungunya e Zika.

Vale ressaltar que este estudo foi realizado com dados secundários de acesso público e que tais informações não permitem a identificação pessoal das mães e nem de seus recém-nascidos, não necessitando de aprovação do Comitê de Ética em pesquisa com seres humanos, estando em consonância com a Resolução 466/12 do Conselho Nacional de Saúde.

\section{RESULTADOS E DISCUSSÃO}

O estudo sobre malformações congênitas apresentou dados das macrorregiões do Estado do Ceará, mais precisamente sobre Fortaleza, Sobral, Cariri, Sertão Central e Litoral leste/Jaguaribe, segundo o DATASUS. O gráfico '1' representa essas informações. 
Gráfico 1. Dados das Malformações Congênitas nas macrorregiões do Ceará.

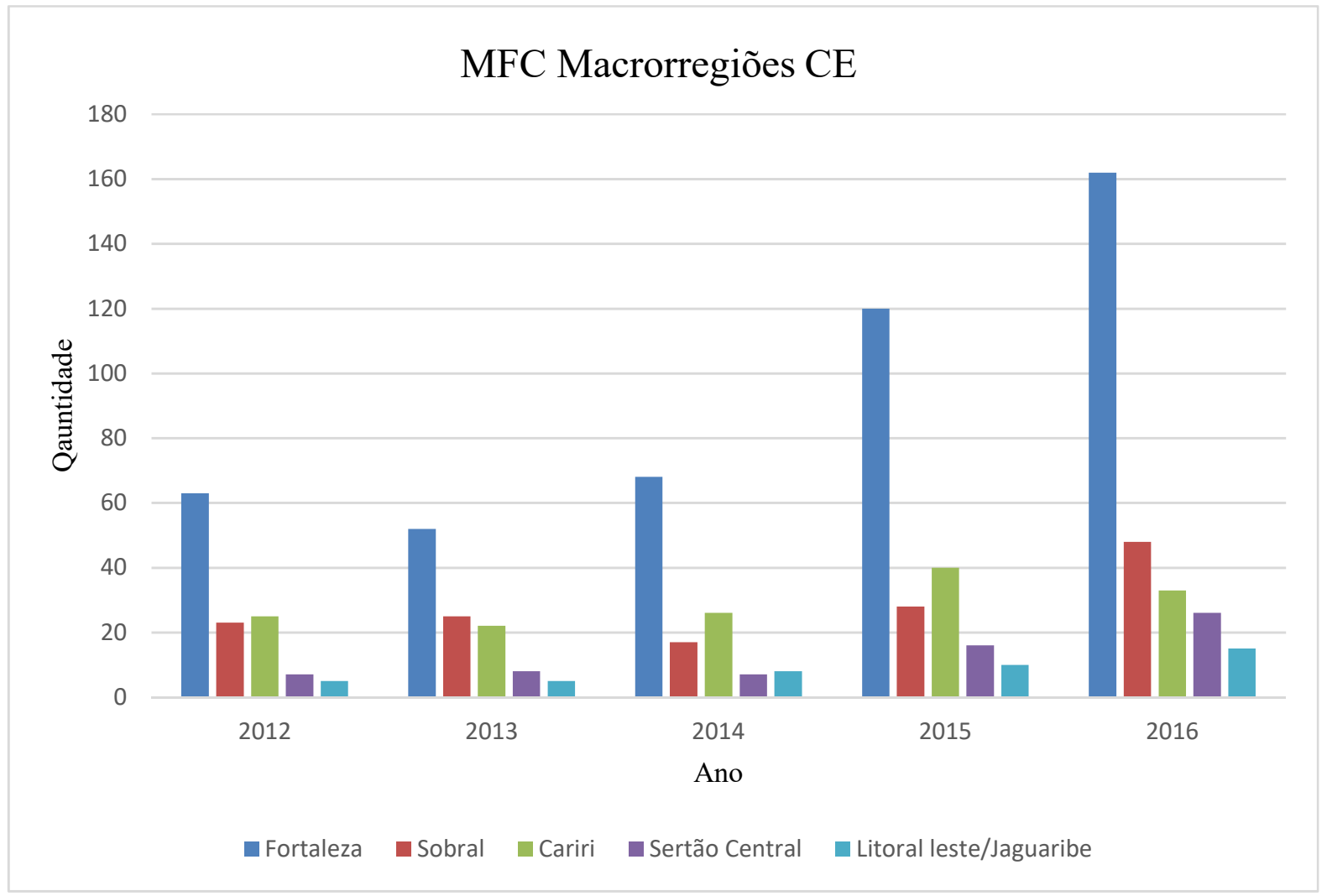

Fonte: Datasus.

No gráfico acima, foi observado que as macrorregiões do Ceará apresentaram índices significativos de casos de defeitos congênitos. Uma causa emergente se deve ao surto de Zika Vírus como citado no estudo de Vasconcelos (2016), gerando preocupação aos setores da saúde pública.

Segundo Leal et al. (2017), registrou-se a incidência de casos de defeitos congênitos em 22 regiões do Estado do Ceará, dentre as quais está a macrorregião de Fortaleza que concentrou o maior número, com mais de 50\%, em fortaleza, entre 2015 e 2017.

O gráfico '2' revela uma situação crescente dos casos diagnosticados como sendo de malformações congênitas relacionadas ao sistema nervoso. No período compreendido entre os anos de 2015 e 2016, sugere-se a influência de infecções adquiridas pelo Zika Vírus, um surto ocasionado pela ação do mosquito Aedes aegypti, como mencionados pelos autores Musso, Nilles, Cao-Lormeau (2014), e na 
pesquisa de Grad et al., (2014), como sendo um dos fatores de malformações congênitas.

Esse agente patogênico é considerado um dos principais problemas de saúde pública, por ser o transmissor de doenças como a dengue, chikungunya, zika e febre amarela, impactando nas medidas preventivas e tratamento (BESERRA et al., 2009).

De acordo com o Ministério da Saúde, o Ceará foi apontado como o Estado com mais mortes por microcefalia em 2015. Entre outubro e agosto do mesmo ano, foram registrados vinte e três óbitos confirmados, sendo oito em Fortaleza (TRIBUNA DO CEARÁ, 2016).

Gráfico 2. Dados dos casos de malformações congênitas em Fortaleza.

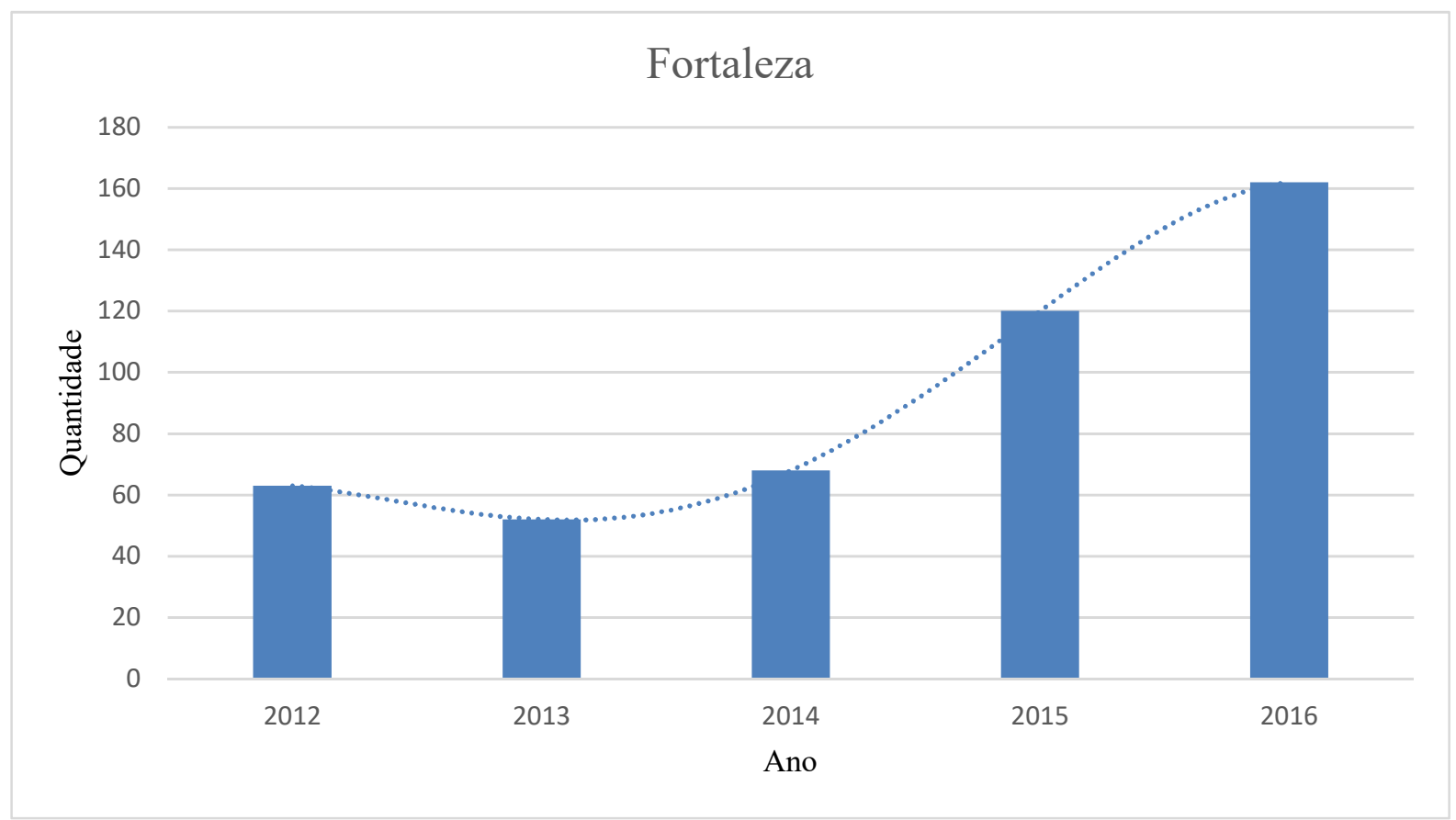

Fonte: Datasus.

A região do Cariri Cearense foi escolhida pelo fato da Universidade Federal do Cariri está localizada nesta região, e por ser um lugar que atrai muitos turistas pela questão cultural, religiosa e apresentar a Chapada do Araripe, referência em arqueologia e biodiversidade de fauna e flora.

Vale ressaltar que, pelo fato das regiões de Fortaleza e Cariri apresentarem estações definidas de chuva e de seca, são localidades de risco para o 
desenvolvimento do mosquito Aedes aegypti. Um aspecto especial são os ovos desse mosquito que podem ficar por longo tempo em estado latente nos locais que acumulam água como pneus, latas, garrafas pet etc., eclodindo ao primeiro contato com a água.

O gráfico ' 3 ' mostra no período estudado que, na região do Cariri Cearense, ocorreram casos de malformações congênitas. No ano de 2016, foram publicados casos de alterações pela técnica de radiologia, sugerindo que se tratava de infecção congênita pelo vírus Zika (HEUKELBACH et al., 2016; RASMUSSEN et al., 2016). Outros estudos enfatizam que dos casos notificados de defeitos congênitos associados ao Zika Vírus, 64,6\% encontravam-se na região nordeste do Brasil, dentre os Estados mais afetados estão Pernambuco, Bahia, Paraíba e Ceará (MINISTÉRIO DA SAÚDE, 2016).

Gráfico 3. Dados dos casos de malformações congênitas no Cariri.

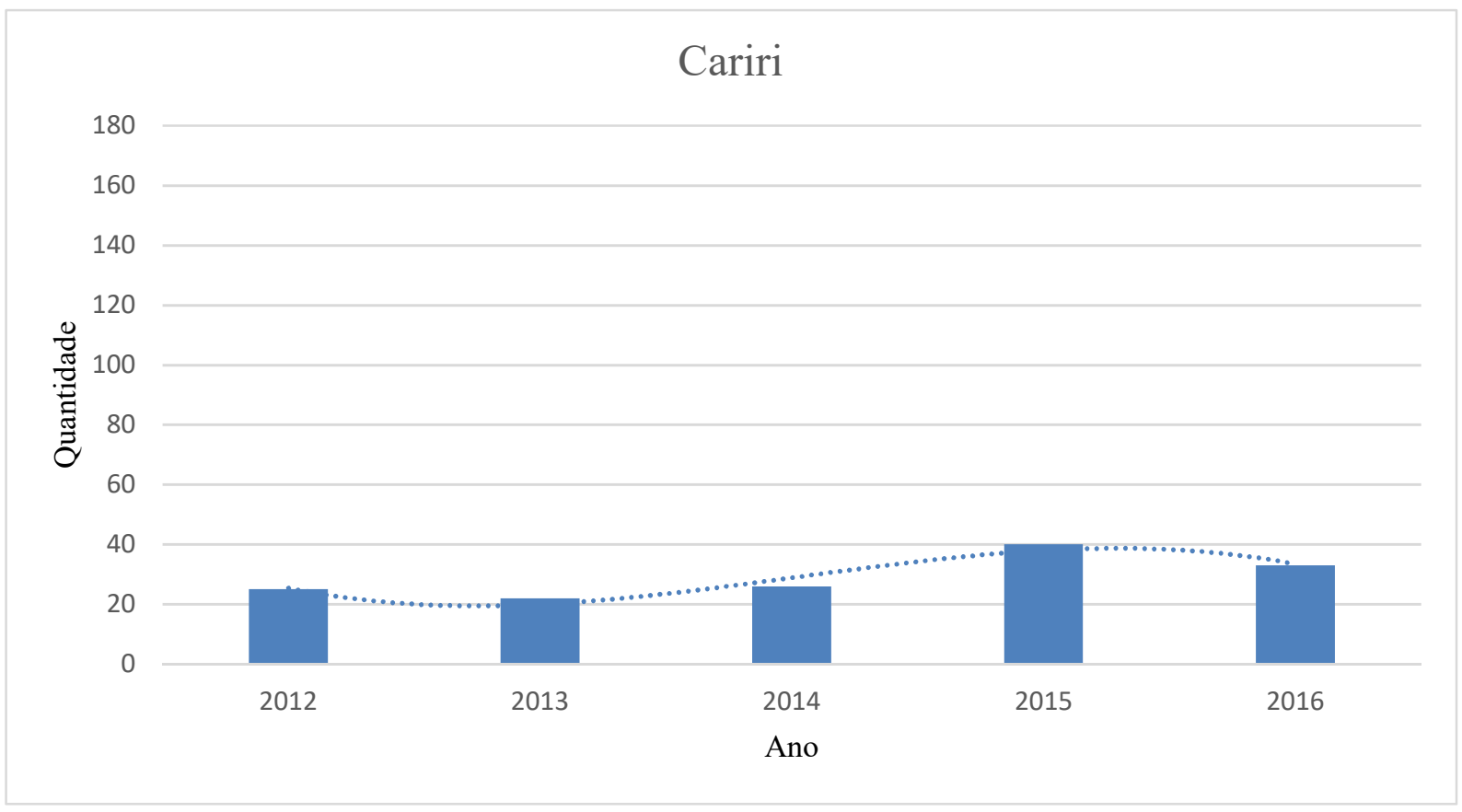

Fonte: Datasus.

Uma situação importante para os casos de defeitos congênitos é a relação da idade materna com os nascidos vivos. Segundo o Ministério da Saúde (2018), as faixas etárias mais afetadas entre os casos notificados compreendem as idades de 20 a 29 anos, representando 75,5\% (77/102) do total de gestantes suspeitas de 
Síndrome Congênita associada à infecção pelo vírus Zika no Estado do Ceará, como evidenciado no gráfico '4'.

Gráfico 4. Informações sobre a idade materna x nascidos vivos.

\section{Idade materna x Nascidos vivos MFC}

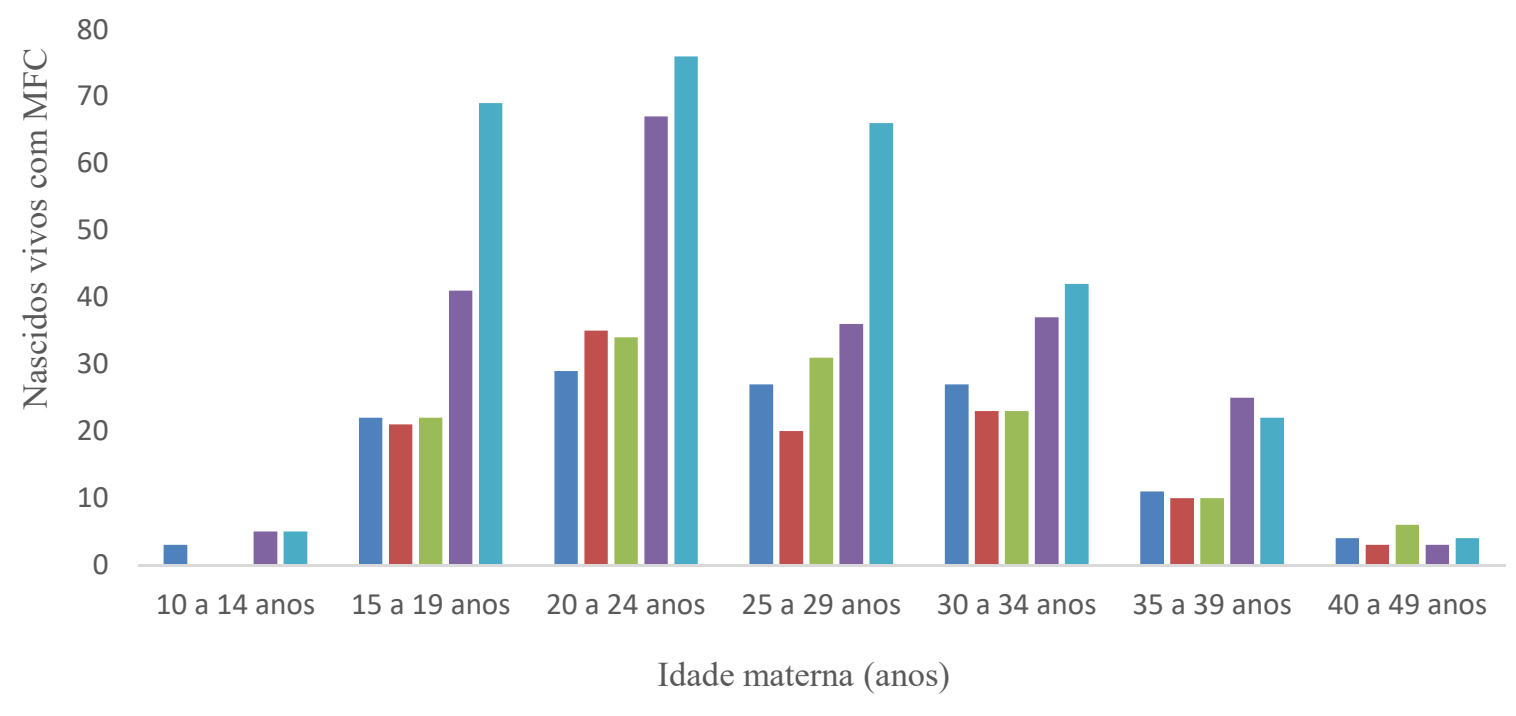

Fonte: Datasus.

Em 2016, até a Semana Epidemiológica (SE) de número 32 que ocorreu entre 03/01/2016 e 13/08/2016, foram registrados 196.976 casos prováveis de febre pelo vírus Zika no Brasil (taxa de incidência de 96,3 casos/100 mil hab.), distribuídos em 2.277 municípios. Dos quais, $132.524(67,3 \%)$ foram notificados em mulheres, contabilizando $96.494(72,8 \%)$ em mulheres com idade fértil (faixa etária de 10 a 49 anos) (MINISTÉRIO DA SAÚDE, 2016).

Os resultados e discussão direcionaram a pesquisa para as macrorregiões do Estado do Ceará, evidenciando as regiões de Fortaleza e Cariri, localidades que recebem muitos turistas e que têm importância socioeconômica, geoambiental e cultural.

Enfatizou-se a questão da presença de estações climáticas definidas como sendo chuvosa e seca, que devem ser levadas em consideração, pois o mosquito causador de várias doenças como a dengue, chikungunya e o Zika Vírus está adaptado a essas condições. 


\section{CONSIDERAÇÕES FINAIS}

O sistema nervoso é a fonte de toda a informação direcionada ao corpo humano, sentidos, pensamentos, estruturas anatômicas e fisiologia que estão associadas ao bom funcionamento do organismo.

A pesquisa realizada objetivou levantar dados sobre a presença de casos de defeitos congênitos com enfoque no sistema nervoso, precisamente na região que abrange o Ceará. Foram alcançadas com o estudo, informações sobre a presença de um vírus que, no período de referência (2012-2016), demonstrou influenciar no aumento de recém-nascidos com anormalidade estrutural e funcional na região crânio-cerebral denominada de microcefalia.

Esse sistema apresenta forte proteção como ossos e outras estruturas, a barreira hematoencefálica e meninges, minimizando danos causados por choques mecânicos externos e ataque de microrganismos. É interessante ressaltar uma particularidade do sistema nervoso, o fluido cerebrospinal, responsável por atuar como protetor e transportador de substâncias, mas que existe uma certa fragilidade quanto ao acesso a esse líquido, podendo ser invadido por alguns microrganismos e apresentar sérios problemas de saúde.

Esses problemas podem ser ocasionados por fatores ambientais e genéticos responsáveis pelo surgimento das malformações congênitas, manifestações que interferem na formação e desenvolvimento do sistema nervoso.

Nos últimos anos, surtos de um vírus conhecido como Zika foi determinante para ações preventivas em muitos estados brasileiros, em especial na região do Nordeste, por ser uma região tropical e apresentar estações definidas de chuva e de seca, proporcionando condições necessárias para o desenvolvimento do mosquito Aedes aegypti.

No Ceará, foi evidente a presença desse agente patogênico, sendo descritos casos em vinte e duas regiões, em especial na macrorregião de Fortaleza que 
concentrou o maior número, num total acima de $50 \%$, confirmando que nessa região há a necessidade de mais atenção das agências de saúde.

O diagnóstico precoce é essencial para a análise da gravidade dos defeitos congênitos causados nos recém-nascidos, desde que se tenha o tratamento adequado para a sobrevida dos bebês e acompanhamento das mães afetadas.

Este estudo apresentou as particularidades inerentes a pesquisas epidemiológicas e que podem direcionar as autoridades governamentais para o investimento em campanhas informativas para a população sobre a prática preventiva contra o surgimento do mosquito Aedes aegypti, transmissor do vírus Zika.

\section{REFERÊNCIAS BIBLIOGRÁFICAS}

AGUIAR, M. J. B.; CAMPOS, Â. S.; AGUIAR, R. A. L. P.; LANA, A. M. A.; MAGALHÃES, R. L.; BABETO, $L$. T. Defeitos de fechamento de tubo neural e fatores associados em recémnascidos vivos e natimortos. J Pediatr. Rio Janeiro, v. 79, n. 2, p. 129-34, 2003.

BESERRA, E. B.; FREITAS, E. M.; SOUZA, J. T.; FERNANDES, C. R. M.; SANTOS, K. D. Ciclo de vida do Aedes (Stegomyia) aegypti (Diptera: Culicidae) em águas com diferentes características. Iheringia, v. 99, n. 3, p. 281-285, 2009.

BRASIL. Ministério da Saúde. Secretaria de Vigilância em Saúde. Monitoramento dos casos de dengue, febre de chikungunya e febre pelo vírus Zika até a Semana Epidemiológica 52, 2016. Boletim Epidemiológico [Internet]. 2017 [citado jun 2018 28];48(3):1-11. Disponível em: http://portalarquivos. saude.gov.br/images/pdf/2017/abril/06/2017-002- Monitoramento-doscasos-de-dengue--febre-dechikungunya-e-febre-pelo-v--rus-Zika-ate-a-SemanaEpidemiologica52--2016.pdf.

BRASIL. Ministério da Saúde. Síndrome Congênita associada a Infecção pelo vírus Zika. Boletim Epidemiológico. p. 3-9, 2018.

BRASIL. Ministério da Saúde. Secretaria de Vigilância em Saúde. Departamento de Vigilância da Doenças Transmissíveis. Protocolo de vigilância e resposta à ocorrência de microcefalia e/ou alterações do sistema nervoso central (SNC). Brasília: Ministério da Saúde, 2016. Disponível em: http://combateaedes.saude.gov.br/images/sala-desituacao/microcefalia-protocolo-de-vigilancia-e-resposta. Acessado em: 19 de outubro de 2018.

BRASIL. Ministério da Saúde. Secretaria de Vigilância em Saúde. Monitoramento dos casos de dengue, febre de chikungunya e febre pelo vírus Zika até a Semana Epidemiológica 47, 2015. Boletim Epidemiológico. v. 46, n. 42, p. 1-9, 2015.

DATASUS. Departamento de Informática do sUS. Disponível em: http://datasus.saude.gov.br/informacoes-de-saude/tabnet. Acesso em: 20 de outubro de 2018.

GARNE, E.; DOLK, H.; LOANE, M.; WELLESLEY, D.; BARISIC, I.; CALZOLARI, E. Paper 5: surveillance of multiple congenital anomalies: implementation of a computer algorithm in European registers for classification of cases. Birth Defects Res A Clin Mol Teratol, p. 44-50, 
2011.

GRAD, G.; CARON, M.; MOMBO, I. M.; NKOGHE, D.; ONDO, S. M.; JIOLLE, D.; FONTENILLE, D.; PAUPY, G.; LEROY, E. M. Zika virus in Gabon (Central Africa) - 2007: a new threat from Aedes albopictus? Plos Neglected Tropical Disease, v. 8, n. 2, 2014. Disponível em: Acesso em: 26 de Outubro de 2018.

HADŽAGIĆ-ĆATIBUŠIĆ, F.; MAKSIĆ, H.; UŽIČANIN, S.; HELJIĆ, S.; ZUBČEVIĆ, S.; MERHEMIĆ, Z.; ČENGIĆ, A.; KULENOVIĆ, E. Congenital Malformations of the Central Nervous System: Clinical Approach. BOSNIAN JOURNAL OF BASIC MEDICAL SCIENCES. v. 8 n. 4, p. 356-360, 2008.

HEUKELBACH, J.; ALENCAR, C.H.; KELVIN, A. A.; OLIVEIRA, W. K.; CAVALCANTI, L. P. G. Zika virus outbreak in Brazil. J Infect Dev Ctries. v. 10, 2, p. 116-20, 2016.

LEAL, A. B.; SILVEIRA, S. M. P.; MIRANDA, J. L.; SOARES, M. D. A. A experiência do Estado do Ceará no enfrentamento à síndrome congênita do Zika Vírus. Campinas, São Paula: Pontes Editores, 2017.

MAYA, G. D. Embriologia Humana. 5. ed. Sao Paulo: Atheneu, 2002.

MOORE, KEITH. L.; PERSAUD, T. V. N.; TORCHIA, MARK G. Embriologia Básica. 9. ed. Rio de Janeiro: Elsevier, 2016.

MUSSO, D.; NILLES, E. J.; CAO-LORMEAU, V. M. Rapid spread of emerging Zika virus in the Pacific área. Clinical Microbiology and Infection, v. 20, n. 10, p. 595- 596, 2014.

ORGANIZAÇÃO PAN-AMERICANA DE SAÚDE (OPS). Prevenção e controle de enfermidades genéticas e os defeitos congênitos: relatório de um grupo de consulta. Washington (US): OPAS, 1984.

SADLER, Thomas W. Langman embriologia médica. 12. ed. Rio de Janeiro: Guanabara Koogan, 2013.

SIMONI, R. Z.; COUTO, E.; BARINI, R.; HENRICH-MOÇOUÇAH, J.; BRAGANÇA, W. O.; COUTO, E. R.; BIZZACHI, J. M. A. Malformações do sistema nervoso central e a presença da mutação C677T-MTHFR no sangue fetal. Instituto de Biologia da Universidade Estadual de Campinas. Revista Brasileira Ginecologia Obstétrica. v. 35, n. 10, p. 436-441, 2013.

VARGAS, A.; SAAD, E.; DIMECH, G. S.; SANTOS, R. H.; SIVINI, M. A. V. C.; ALBUQUERQUE, L. C.; LIMA, P. M. S.; BARRETO, I. C.; ANDRADE, M. E.; ESTIMA, N. M.; CARVALHO, P. I.; AZEVEDO, R. S. A.; VASCONCELOS, R. C. O.; ASSUNÇÃO, R. S.; FRUTUOSO, L. C. V.; CARMO, G. M. I.; SOUZA, P. B.; WADA, M. Y.; OLIVEIRA, W. K.; HENRIQUES, C. M. P.; PERCIO, J. Características dos primeiros casos de microcefalia possivelmente relacionados ao vírus Zika notificados na Região Metropolitana de Recife, Pernambuco. Epidemiol. Serv. Saude, Brasília, v. 25 n. 4, p. 691-700, 2016.

VASCONCELOS, C. M. ABORDAGEM ECO-BIO-SOCIAL PARA O CONTROLE DAS DOENÇAS TRANSMISSÍVEIS PELO Aedes aegypti: UMA INTERVENÇÃO EM LARGA ESCALA NO BRASIL. Centro de Ciências da Saúde. Universidade Estadual do Ceará Fortaleza, CE, 2016.

YADAV, S.; RAWAL, G.; BAXI, M. Zika virus: an emergence of a new arbovirus. J Clin Diagn Res. v. 10:DM01-3, 2016.

YOUNGER DS. Epidemiology of Zika virus. Neurol Clin. v. 34, p. 1049-56, 2016. 